to teaching as their principal activity. Research and development occupied 35 per cent of all scientists, while administration and various managerial activities took 21 per cent.

The details of salary will probably command the closest attention-not only among those about to emigrate to the United States. In 1964 the median salary for scientists in the United States worked out at $\$ 11,000$, but there were significant variations from discipline to discipline, age to age, and even from place to place. The median salaries of economists, physicists and statisticians were $\$ 1,000$ above par. Chemists and mathematicians had median salaries of $\$ 11,000$, but other disciplines fell below par with agricultural scientists near the bottom of the list with median salaries of $\$ 9,200$. The possession of a Ph.D. degree seems to confer an advantage of $\$ 2,000$ in salary --the difference between the median salary of $\$ 12,000$ for doctors and $\$ 10,000$ for those with master and bachelor degrees. It is plain that the management and administration of research and development is more rewarding (median salary $\$ 15,500$ ) than research and development itself (median $\$ 11,000$ ), although this comparison is in part vitiated by the predominance of scientists with doctorates among the administrators. The median salary in industry or commerce worked out at $\$ 12,000$. The corresponding figure for educational institutions was $\$ 9,600$-a figure calculated on the basis of an academic year of nine or ten months for a good many teachers.

For all scientists, the upper and lower quartiles of the salary distribution lie at $\$ 14,000$ and $\$ 8,600$. Predictably, there is more uniformity among the lower quartile salaries earned in different specialities than among the upper quartiles, which range from $\$ 11,200$ (for agricultural scientists) to $\$ 16,000$ for economists. Economists are among the most highly paid of the scientists and social scientists on the national register, and 10 per cent of them earned more than $\$ 20,000$ in 1964. Among the pure scientists, straightforward biologists seem to have done slightly better than physicists and mathematicians, with an upper decile of $\$ 19,000$ (compared with $\$ 18,700$ for physics and $\$ 18,500$ for mathematics). Women, who account for $7 \cdot 6$ per cent of the scientists on the register, earn less than men. Their median salary works out at $\$ 8,400$, with the greatest rewards in the social sciences. Undoubtedly a part of this apparently unflattering comparison is to be explained by differences of age distribution and even of qualification between the sexes. Salaries increase with age up to the late fifties, with a median of $\$ 7,000$ between 20 and 24 and a plateau of about $\$ 13,000$ or just above which seems to be reached in the late forties.

\section{Mintech Marriage}

THE Ministry of Aviation was formally merged within the Ministry of Technology on February 21, after some hectic days in the House of Commons when it seemed as if the enabling legislation would be defeated by procedural difficulties. In the new ministry Sir Richard Clarke will remain the administrative head. Sir Richard Melville, hitherto Permanent Secretary at the Ministry of Aviation, will become head of the Aviation Group. The direction of the scientific establishments is to be shared between Dr. George MacFarlane and Mr. Ieuan Maddock. Dr. MacFarlane, at present director of the Royal Radar Establishment, will become Controller (research) with responsibility for the research stations already within the ministry, the Atomic Energy Authority, the National Research Development Corporation, the research associations and, eventually, the research establishments transferred from aviation. Mr. Maddock will be Controller (industrial technology), and will be responsible for the work of the ministry in promoting development within the engineering industry.

\section{Jobs for Biologists}

BRITISH biologists who are looking for jobs will take heart from the results of a survey carried out by the Institute of Biology ( $A$ Survey of the Employment of Graduates in Biological Posts in the United Kingdom : J. Inst. Biol., 13, 131; 1966). The survey made use of published information on the specialization of biologists in the Civil Service, government research and education, and detailed questionnaires were sent to companies to obtain information about biologists in industry. The survey should put an end to the myth that biology graduates have poor prospects of employment. Of the eleven thousand graduate biologists employed in the principal British centres, nearly five thousand are teachers, chiefly in secondary schools. Another five thousand are about equally divided between state aided research and the universities, and the remaining fifteen hundred are employed in industry. There are 1,085 biochemists, 868 microbiologists, and 797 animal physiologists-the 4,143 general biologists are almost all engaged in teaching.

The form of the survey made it possible for the institute to estimate the rate of growth of the demand for biology graduates. Certain specialities, such as microbiology and toxicology, seem to be inadequately supplied with qualified people. The demand from industry so much exceeds the supply of such graduates that the additional requirement by June 1967 will be 25 per cent of the existing number of industrial microbiologists. Many of the available posts in such specialities are, of course, filled by scientists from related disciplines, but companies often find that it is expensive to retrain such people. The institute thinks there is a case for more specialized courses at the undergraduate level in subjects like industrial microbiology, and for establishing new departments where these do not already exist. Such a solution would solve the immediate problems for industry, but it would be at the expense of any attempts there might be to broaden the horizon of biology teaching in the universities. The proper place for specialized teaching of this sort is at the graduate level, and it is encouraging to see that many universities are now starting all their biology students on a general biology course.

Industry expects a rate of growth in the demand for biologists of 10-15 per cent each year. The universities are working on the assumption that they will require about 7 per cent more biology graduates each year. Applied biologists should benefit most from this labour shortage, but university and research biologists will also be assured of a place. 